\title{
Reflexões sobre o conceito de Autonomia para o Ensino de Ciências: elementos da filosofia de Cornelius Castoriadis como fundamento para a crítica da pós-verdade ${ }^{+}$
}

\author{
Midiã Medeiros Monteiro ${ }^{1}$ \\ Universidade Federal Rural do Semi-Árido \\ Mossoró - RN \\ Márcia Gorette Lima da Silva \\ Universidade Federal do Rio Grande do Norte \\ Natal - RN
}

\section{Resumo}

Um importante aspecto que diz respeito ao Ensino de Ciências (EC) e que acreditamos permanecer com lacunas a serem preenchidas diz respeito ao seu objetivo. Este artigo tem como foco discutir a autonomia como um objetivo para o EC, esta pensada à luz da perspectiva filosófica de Cornelius Castoriadis. Em concreto, nos propomos reflexões em três direções, inicialmente interrogar a concepção de formação humana e o objetivo do EC apontando a autonomia como um sentido para pensar esta formação; em seguida, apresentar a perspectiva filosófica de Cornelius Castoriadis e o seu Projeto de Autonomia, considerando sobretudo os conceitos de imaginário, imaginação e instituições sociais, sustentando que a criticidade figura como um de seus elementos constitutivos e; por fim, defender a ideia de que essa perspectiva pode contribuir para a reflexão sobre o EC na superação da ideia de pós-verdade. É na análise crítica das afirmações de conhecimento que situamos a autonomia, podendo parecer paradoxal pensá-la em oposição à pós-verdade quando se concebe nela uma possível relativização da verdade, mas que enseja uma crítica a verdade.

\footnotetext{
${ }^{+}$Reflections on the concept of Autonomy for Science Education: elements of Cornelius Castoriadis's philosophy as a basis for criticism of the post-truth

* Recebido: junho de 2020. Aceito: novembro de 2020.

${ }^{1}$ E-mails: midia.monteiro@ufersa.edu.br; marciaglsilva@yahoo.com.br
} 
Palavras-chave: Autonomia; Ensino de Ciências; Cornelius Castoriadis; Criticidade.

\begin{abstract}
An important aspect that concerns Science Education (SE) and that we believe still remains with gaps to be filled concerns its objective. This article focuses on discussing autonomy as an objective for SE, this thought in the light of Cornelius Castoriadis' philosophical perspective. Specifically, in this article we propose reflections in three directions, initially questioning the concept of human formation and the objectives of Science Education, pointing to autonomy as a possible meaning to think about this formation; then, to present the philosophical perspective of Cornelius Castoriadis and his Project of Autonomy, considering above all the concepts of imaginary, imagination and social institutions, maintaining that the criticality figures as one of its constitutive elements and; finally, how this perspective can contribute to the reflection on the $S E$, in overcoming the idea of post-truth. It is in the critical analysis of the statements of knowledge that we situate autonomy, and it may seem paradoxical to think of it in opposition to post-truth, when a possible relativization of the truth is conceived, but which gives rise to the criticism of the truth.
\end{abstract}

Keywords: Autonomy; Science Education; Cornelius Castoriadis; Criticism.

\title{
I. Introdução
}

Autonomia é uma palavra bem conhecida nos campos da Educação de forma geral e do Ensino de Ciências (EC) em particular. Basta uma busca rápida em algumas plataformas de trabalhos acadêmicos para identificar a extensão de pesquisas relacionados a essa temática $^{2}$. Diferentes abordagens didáticas apoiam suas defesas na perspectiva de uma formação que busca a promoção da autonomia (BERBEL, 2011; SOUZA; CARVALHO, 2005; MELO, 2016; ALCÂNTARA, 2018). No que concerne a legitimidade legal na defesa

2 Por exemplo, quando inserimos no campo de busca da Plataforma Sucupira a palavra 'Autonomia' identificamos 18.982 (dezoito mil, novecentos e oitenta e dois) trabalhos, limitando a busca à área de conhecimento da Educação e do Ensino, passamos ao universo de 4.619 (quatro mil seiscentos e dezenove) (endereço de busca: <http://catalogodeteses.capes.gov.br/catalogo-teses/\#!/> acesso em: 27 mai. 2020). Buscando no Scielo, encontramos 6.301 (seis mil, trezentos e um) trabalhos e, limitando-nos a textos em português, da área (WOS) de Educação, temos um universo de 808 (oitocentos e oito) trabalhos identificados (endereço de busca $<$ https://scielo.org/>. Acesso em: 27 mai. 2020). 
da autonomia como parte integrante da Educação, a Lei de Diretrizes e Bases da Educação Nacional 9394/96 (LDB96) quando das suas finalidades afirma: “[...] o aprimoramento do educando como pessoa humana, incluindo a formação ética e o desenvolvimento da autonomia intelectual [...]” (BRASIL, LDB, art. 35, § III).

Mais recentemente, a Base Nacional Curricular Comum (BNCC) reafirma as finalidades educacionais presentes na LDB96, concordando com uma formação que desenvolva a autonomia. É interessante observar nesse documento que a autonomia aparece como qualidade adquirida, por vezes é dada como algo necessariamente alcançado nas etapas formativas antecedentes, p.ex., "[...] as crianças constroem sua autonomia e senso de autocuidado, de reciprocidade e de interdependência com o meio" (BRASIL, BNCC, p. 40), e ainda: "[...] ampliam-se a autonomia intelectual, a compreensão de normas e os interesses pela vida social [...]" (Ibidem, p.59). Nesses trechos a autonomia aparece como uma qualidade adquirida. Mas, o que vem a ser a autonomia? É possível desenvolver indivíduos autônomos(as)? Esse deve ser um sentido da formação humana e da formação científica? Acreditamos que a concepção de autonomia é, por vezes, abstrata demais e sua adoção é tratada de forma muito superficial.

Assumimos que uma Educação comprometida com o desenvolvimento da autonomia deve estar envolta em três princípios, a saber: a sala de aula como espaço democrático, a imaginação na sua dimensão radical $^{3}$ e a disposição para criticidade. No domínio deste artigo vamos discutir o último princípio a fim de apontar como este contribui para problematizar o atual debate em torno da pós-verdade. Vale destacar que estes princípios são interdependentes e igualmente importantes e, é apenas por uma questão de atender ao propósito aqui prescrito, e pela relação que procuramos estabelecer entre esse e a possibilidade de problematizar a pósverdade, que iremos nos ater a aprofundar o terceiro princípio ${ }^{4}$.

Em concreto, nos propomos reflexões em três direções: inicialmente, interrogar a concepção de formação humana e o objetivo do EC apontando a autonomia como um sentido para pensar esta formação; em seguida, apresentar a perspectiva filosófica de Cornelius Castoriadis e o seu Projeto de Autonomia, considerando sobretudo os conceitos de imaginário, imaginação e instituições sociais, sustentando que a criticidade figura como um de seus elementos constitutivos e; por fim, defender a ideia de que essa perspectiva pode contribuir para a reflexão sobre o EC na superação da ideia de pós-verdade. É na análise

\footnotetext{
3 O termo dimensão radical está relacionado o conceito castoriadiano imaginação que será discutida no decorrer do presente artigo.

${ }^{4}$ Este artigo é parte de nossa pesquisa de doutorado que se encontra em desenvolvimento. A principal finalidade da tese é discutir uma perspectiva formativa que vise a autonomia e sua relação com as abordagens didáticas da História, Filosofia e Sociologia das Ciências (HFSC) e da Argumentação Científica (AC) à luz das ideias filosóficas de Cornelius Castoriadis. Como um dos objetivos, nos propomos (re)pensar a formação no EC, encontrando na autonomia um sentido e na perspectiva filosófica de Castoriadis uma direção. A partir daí traçamos caminhos que buscam subsidiar uma formação com vistas à autonomia. Nessa direção, estabelecemos o que ora denominamos Princípios Pedagógicos para Autonomia, que foram acima apenas mencionados. Aqui, não é nosso objetivo discutir cada um desses princípios.
} 
crítica das afirmações de conhecimento que situamos a autonomia, podendo parecer paradoxal pensá-la em oposição à pós-verdade quando se concebe nela uma possível relativização da verdade, mas que enseja uma crítica a verdade.

\section{Um sentido para a formação humana e para o Ensino de Ciências}

Ao situar-nos do campo da Educação de uma forma mais geral e do EC, mais especificamente, muitas são as dimensões que podem ocupar as problemáticas de nossas pesquisas nessas áreas. Podemos, entretanto, agrupá-las na direção de responder às perguntas de tipo: Para quê ensinar? Por quê ensinar? O que ensinar? Como ensinar?

O que é mais comum na produção científica dessas áreas e nos cursos de formação docente, a ênfase nos aspectos sobre o que ensinar e o como ensinar? Um exercício de anamnese sob nossa própria formação é capaz de evidenciar quanto tempo dela foi destinado aos conteúdos específicos do nosso campo de saber e, possivelmente em uma menor medida, mas existente, às técnicas de ensino desse saber. Será que houve espaço de reflexão sobre o para quê? e o por quê? Qual o sentido da formação humana 5 ? E, qual o sentido do EC como parte integrante dessa formação?

Diferentes pensadores se dedicaram/dedicam ao (re)exame das finalidades da formação humana (ADORNO, 1995; RODRIGUES, 2001; VALLE, 2002; SEVERINO, 2006; VALLE, 2008; FREIRE, 2004). Tal reflexão é central na Filosofia da Educação, mas não é distante das diferentes áreas do conhecimento que dialogam com a Educação, assim como o é na área de EC (EL-HANI; MORTIMER, 2007; LIMA; NASCIMENTO, 2019; MOURA, 2012; MOURA, 2019). Pensar a formação é, além de um exercício pedagógico, um exercício ético e político. Significa estabelecer que tipo de sujeito/sociedade se tem como modelo, é uma busca por sentido, este historicamente constituído. Portanto, é possível afirmar que ao longo da história revelaram-se diferentes perspectivas para formação humana ${ }^{6}$.

Ferreira (2015) discute sobre o debate entre Godman e Siegel acerca do objetivo do EC afirmando que no primeiro o objetivo está centrado no conhecimento enquanto no segundo seria o entendimento ${ }^{7}$. Em Oliveira (2017) também podemos encontrar uma síntese do debate em torno do que deve se constituir como objetivo do EC, que dentre outros pontos

\footnotetext{
${ }^{5}$ Tomamos aqui formação humana no seu sentido mais amplo possível, sendo a Educação uma das suas dimensões mais relevantes nas sociedades modernas. Castoriadis (2006, p.58) quando discute o processo de socialização dos sujeitos menciona: "E, como já sabia Platão, os próprios muros da cidade socializam”.

${ }^{6}$ Para uma compreensão histórica desses sentidos ver: Rodrigues (2001) e Severino (2006).

${ }^{7}$ Ainda que partindo de uma discussão epistemológica distinta da nossa, Ferreira (2015) defende a tese de que o objetivo do EC é a formação de sujeito virtuoso, destacando o entendimento e a autonomia como virtudes fundamentais.
} 
aponta para um EC que deveria promover mudanças nas crenças dos estudantes, aproximando-as das Ciências ou promover o entendimento das teorias e modelos científicos ${ }^{8}$.

A escola é uma instituição social e enquanto tal cumpre o papel de fabricação social dos sujeitos ${ }^{9}$ que consiste em "[...] domar a psique levando-a a criar um estrato psíquico perfeitamente apropriado ao funcionamento daquilo que será o indivíduo nessa sociedade" (CASTORIADIS, 2007, p.63). Ora, se há algo em comum nas distintas instituições sociais é a característica de conservação da sua estrutura para sua própria manutenção e coesão social. Nesse sentido, é a escola um espaço privilegiado de educação "[...] destinada à formação de subjetividades, à produção de sujeitos, à construção e veiculação de identidades, à definição de lugares de sujeitos" (ALBUQUERQUE JÚNIOR, 2010, p.55) de forma consciente e deliberada e, é importante que os(as) docentes entendam a condição política ${ }^{10}$ desta atividade.

Para Albuquerque Jr. (2010) a escola, de todas as instituições sociais criadas pela modernidade, é a mais exemplar por ter na constituição dos sujeitos uma atividade consciente e deliberada, que ainda é possuidora de prestígio social. Entretanto, sua crise é anunciada por muitas vozes clamando também por uma necessária reforma. No que se refere ao EC, como não lembrar da obra $A$ necessária renovação no ensino de ciências? (CACHAPUZ et al., 2005).

A formação que ora criticamos, e que muitos já o fizeram, é aquela centrada na manutenção do status quo com ênfase em uma racionalidade técnica e instrumental, condicionada pelo capital, com foco apenas nos conteúdos conceituais dissociando esse mesmo conteúdo de sua própria constituição e deste com a sociedade, que tem na figura do(a) professor(a) um depositário de informações. O que defendemos é uma formação capaz de conduzir os sujeitos à reflexão e auto reflexão sobre a sua realidade com vista a pensar certo $^{11}$, a (con)viver, agir e transformar a sociedade, de se reconhecer integrante de uma cultura que é historicamente constituída.

Deseja-se que a escola possibilite aos estudantes desenvolver o pensar com apoio do EC, a desenvolver um modo de pensar específico, o modo de pensar das Ciências ${ }^{12}$. E não

\footnotetext{
${ }^{8}$ A partir da perspectiva do anarquismo filosófico de Feyerabend, Oliveira (2017) defende a tese de que o EC deve considerar como objetivo a diversidade de formas de conhecimento, de culturas e modos de vida contribuindo para o entendimento científico e o desenvolvimento da autonomia intelectual dos(as) estudantes.

${ }^{9} \mathrm{Na}$ próxima seção aprofundaremos as categorias analíticas que Castoriadis utiliza para discutir A Instituição Imaginária Social Imaginação, dentre elas, instituição social e das representações de sentidos que impõe.

${ }^{10}$ Aqui empregamos o termo política na dimensão definida por Castoriadis (2000, p. 123) como uma "[...] aticvidade colectiva, reflectida e lúcida, que visa a instituição global da sociedade".

${ }^{11}$ Tomamos pensar certo na perspectiva freireana (FREIRE, 2004).

${ }^{12}$ Com essa afirmação, não estamos sustentando que as Ciências têm uma única forma de constituição, um método rígido, único, mas afirmando a existência de práticas que as constituem e que balizam suas afirmações de conhecimento, ainda que essas balizas sejam historicamente definidas.
} 
apenas pensar, mas pensar e voltar a pensar no pensado e no impensado ${ }^{13}$. Freire (2004) defende a necessidade de pensar certo ou ainda em ser mais. Pensar certo e ser mais deve ter ligação direta com a realidade, por isso a ênfase em uma educação que contemple a realidade objetiva dos/as educandos, pois a formação humana deve servir ao mundo da vida, como afirma:

\begin{abstract}
Por que não discutir com os alunos a realidade concreta a que se deva associar a disciplina cujo conteúdo se ensina, a realidade agressiva em que a violência é a constante e a convivência das pessoas é muito maior com a morte do que com a vida? Por que não estabelecer uma "intimidade" entre os saberes curriculares fundamentais aos alunos e a experiência social que eles têm como indivíduos? Por que não discutir as implicações políticas e ideológicas de um tal descaso dos dominantes pelas áreas pobres da cidade? (FREIRE, 2004, p. 22).
\end{abstract}

Ainda na perspectiva da necessidade de pensar suas condições de constituição para pensar certo, Freire (2004, p.27) afirma:

Por outro lado, quanto mais me assumo como estou sendo e percebo a ou as razões de ser de porque estou sendo assim, mais me torno capaz de mudar, de promoverme, no caso, do estado de curiosidade ingênua para o de curiosidade epistemológica.

Na perspectiva de construção de sentidos para a formação humana, acreditamos que a autonomia é um caminho que atende não apenas a dimensão da construção de um sujeito pensante presente, mas também de um sujeito pensante atuante para um mundo que está por se constituir, entendendo a constante capacidade de transformação social.

A autonomia enquanto objetivo de ensino não é inexistente em trabalhos de pesquisa que discutem o EC. É comum que em defesa de diferentes abordagens didáticas recorra-se ao argumento de que esta contribui para a construção de sujeitos autônomos. No entanto, isso é possível? O que significa um ensino que vise a autonomia? Qual(ais) direção(ões) que contribuem para uma formação com esse propósito? Como isso materializa-se na prática de sala de aula? Ora, se a autonomia é estabelecida como um parâmetro para o ensino em suas diferentes etapas, é preciso ter clareza do que se entende e se assume como autonomia e pensar estratégias para fomentá-la.

Formar para autonomia implica possibilitar aos sujeitos o reconhecimento de sua responsabilidade ética, histórica, política e social de participar, intervir no mundo e não apenas de conhecê-lo. É comum no EC a manifestação do discurso de importância do conhecimento científico para balizar o exercício da cidadania, da responsabilidade de pensar cientificamente as questões sociais, de tomar decisões conscientes. Mas, essa capacidade não

\footnotetext{
${ }^{13}$ Essa é em nossa perspectiva uma das grandes contribuições do EC, a pensar o que já pensaram confirmando essa forma de pensar ou confrontando suas concepções às Ciências e, a aprenderem sobre o jamais pensado.
} 
se desenvolve apenas ancorando-se em conhecimentos conceituais específicos (embora fundamentais). Mas, requer "[...] exame crítico da atividade de instituição das crenças, valores, aspirações, hábitos que definem o modo de ser coletivo e o modo de ser particular de cada um" (VALLE, 2008, p. 496). Esta perspectiva de possibilitar conhecer e criar de forma refletida e deliberada é sinalizada pela autora ao afirmar que:

\section{[...] a autonomia implica exatamente isso: o fato de que o que são o humano e a sociedade não se encontra inscrito em uma natureza cujas leis e regularidades, de antemão fixadas, podem assim ser previamente conhecidas, mas depende, a cada vez, de uma criação individual e social arbitrária, que pode e deve ser submetida a questionamento (VALLE, 2008, p. 508).}

Etimologicamente, autonomia é uma palavra que para o português vem do francês autonomie e que encontra origem nos vocábulos gregos autós (por si mesmo) e nomos (leis). De maneira hegemônica, o conceito de autonomia seria, pois, a condição de dar a si mesmo sua própria lei. No opúsculo 'Resposta à Pergunta: o que é esclarecimento? ${ }^{14}$ ' Kant (1985, p. 100) afirma: "Esclarecimento é a saída do homem de sua menoridade [...]", esta, definida como sendo "[...] a incapacidade de fazer uso de seu entendimento sem a direção de outro indivíduo". Em Kant, o indivíduo por uso da sua racionalidade ${ }^{15}$ deve se autogovernar, ser o legislador de si mesmo. $\mathrm{Na}$ disputa entre a causalidade pela natureza (relativo aos desejos, impulsos) e a causalidade pela liberdade (relativa à razão) é a primazia da razão que mitiga os impulsos e concede ao indivíduo o livre-arbítrio. Mas, a perspectiva kantiana não considera que a própria racionalidade é moldada dentro de um sistema de representação sócio-histórica e é condicionada por este.

Então, se a própria racionalidade é uma construção social, como é possível pensar em autonomia? Castoriadis nos oferece outra perspectiva para pensar a autonomia dentro de um quadro que concebe o indivíduo como um ser sócio-histórico, mas dotado de capacidade de criação. A autonomia aqui assumida é aquela que encontra nas ideias de Castoriadis suas bases filosóficas. A motivação para agir é exterior e interior. Daí a importância da perspectiva de compreensão dos indivíduos e da sociedade presente nas ideias de Castoriadis, que nega a dicotomia indivíduo-sociedade. Tal aspecto implica uma espécie de heteronomia, mas uma heteronomia sem sujeição ou servidão. Propomos, então, uma apresentação de alguns dos conceitos que acreditamos fundamentais para compreender o Projeto de Autonomia em Castoriadis.

\footnotetext{
${ }^{14}$ Kant utiliza o termo 'Aufklärung' que tem em português o correspondente a 'esclarecimento', mas é possível considerar esclarecimento e autonomia como sinônimos (KANT, 1985).

${ }^{15}$ Para Kant é a Razão o atributo que evidencia a essência humana o diferenciando dos outros animais.
} 


\section{Uma Filosofia para a Educação presente na visão de Castoriadis}

Filósofo, pensador político, crítico social, economista e psicanalista, Cornelius Castoriadis, nasceu em 11 de março de 1922, em Constantinopla-Grécia, hoje Istambul. Pouco depois de seu nascimento, para escapar dos conflitos entre Grécia e Turquia, sua família migrou para Atenas. Estudou Direito e Ciências Econômicas e Políticas e, aos 23 anos mudou-se para a França, após receber uma bolsa de estudos. Fez carreira como economista na OCDE até 1970. No período de 1981 a 1997 exerceu atividades de orientador de pesquisas na École des Hautes Études en Sciences Sociales, em Paris, além de estudar e praticar a Psicanálise. Viveu ali até sua morte em 26 de dezembro de 1997, aos 75 anos de idade ${ }^{16}$.

Dentre suas obras mais conhecidas estão: i) A instituição imaginária da sociedade, publicada em 1975, em que ele analisa a constituição de uma sociedade desenvolvendo suas principais categorias analíticas: imaginário, imaginação, social-histórico, instituição; ii) As encruzilhadas do Labirinto, composta de seis volumes, sendo o último póstumo, onde dá prosseguimento ao projeto de compreensão da sociedade e de sua criação imaginária. Foi um projeto inacabado, que começou em 1978 e prosseguiu até a sua morte em 1997. Todos estes volumes reúnem textos publicados anteriormente em diferentes veículos, revistas de diversas áreas, transcrições de conferências, seminários, palestras, entrevistas, capítulos de livros etc. Estão organizados em partes que compreendem, frequentemente, as mesmas divisões: Kairós - reúne as entrevistas e escritos mais casuais; Psyché - traz os escritos de sua perspectiva psicanalítica; Koinonía - aborda as questões referentes a sociedade; Logos - compreende seus textos de reflexão filosófica e sobre a ciência; Polis - abarca seus escritos de natureza mais política.

No tocante ao aspecto filosófico, defendeu a necessidade de uma nova ontologia à fim de possibilitar o desenvolvimento de uma sociedade autônoma e inaugurou um Projeto de Autonomia tendo como sustentação o papel criador do espírito humano, negando o determinismo da filosofia herdada ${ }^{17}$ e anunciando a importância da imaginação e do imaginário na constituição dos indivíduos e das sociedades.

\footnotetext{
${ }^{16}$ Para conhecer mais sobre Castoriadis indicamos a biografia Castoriadis, una vida (DOSSE, 2018). Além disso, o site $<$ http://www.agorainternational.org/> mantém uma série de trabalhos de e sobre Castoriadis, além de inúmeras informações, p. ex., Colóquios Internacionais.

${ }^{17}$ Para Castoriadis a filosofia herdada carrega em si uma base racionalista que pressupõe uma relação de causalidade bem definida. Mas, por admitir a essência humana como capacidade de criação (de produção do indefinido, do que não é dado), as determinações no que dizem respeito a humanidade não são possíveis. Isso não quer dizer que não seja possível compreender e explicar a realidade. Ele não nega a existência da causalidade, mas reforça a ideia de existências de relações não deterministas. Influenciado pela psicanálise entende que as ações inconscientes são muito presentes e influenciam as práticas sociais, com resultados não planejados, mas que apresentam uma aparente coerência e lógica globais. É a instituição das significações sociais (que trataremos mais adiante).
} 
A perspectiva de Castoriadis nos permite relacionar a Educação a uma atividade para praxis $^{18}$. Mas, como o conhecimento se relaciona com a vida prática? Qual a relação possível entre teoria e prática? Para o autor, o pleno sentido da teoria é aquilo que ela é capaz de inspirar na prática, o que leva a estabelecer as bases daquilo que podemos chamar de sua filosofia é a necessidade de compreender como indivíduo/sociedade se comporta e aquilo que rege sua ação prática, isso porque ele tinha como objetivo a possibilidade de transformação social.

A ideia de que ação consciente é precedida de uma teoria total não corresponde ao que Castoriadis acreditava. Para elucidar a relação entre o fazer e o saber, ele propõe pensar em dois possíveis extremos: da atividade puramente não consciente e da atividade puramente racional. Tomando a primeira, o fazer não estará ligado a nenhum saber, entretanto, seria uma atividade fora da história, o que é impossível (excluindo, determinadas atividades biológicas, como respirar p. ex.). Para a segunda possibilidade, o fazer estaria associado a um saber exaustivo ou praticamente exaustivo dentro de seu domínio, bastariam determinar as causas que levariam a um resultado desejado, tal fato existe e é realizado na técnica, entretanto, nenhuma técnica explica todos os fins a que serve.

Castoriadis constrói um conjunto de reflexões que tenham ressonância em uma prática revolucionária, assim a temática da autonomia é central nas suas obras. "É autônomo aquele que dá a si mesmo suas próprias leis" (CASTORIADIS, 2004, apud ROIZ, 2009, p.102). Aparentemente para esta afirmação não há contradição entre a perspectiva de autonomia de Castoriadis e a de Kant, entretanto, isso não é verdade, uma vez que para Castoriadis as leis que nos damos não é um exercício puro de livre arbítrio. Para entendermos a diferença é necessário destacar algumas categorias que ele assume, criação, imaginação/imaginário e instituições sociais.

A concepção de criação é central para sua filosofia e está integrada a todas as outras dimensões de compreensão de sua dinâmica social. Considerando a singularidade como característica essencial do ser, ele questiona: “[...] podemos pensar esta relação original que faz com que cada homem ou cada sociedade sejam o que são, não apesar de sua singularidade, mas em função de sua singularidade?” (CASTORIADIS, 1992, p. 84). Para dar resposta a essa pergunta ele postula a criação. Define então criação como uma capacidade dos humanos, uma essência ${ }^{19}$ (contrariando os existencialistas que negam que há uma natureza

\footnotetext{
${ }^{18}$ Definida como: "fazer no qual o outro ou os outros são visados como seres autônomos e considerados como o agente essencial do desenvolvimento da sua própria autonomia" (CASTORIADIS, 1982, p. 94). Castoriadis diferencia atividade teórica e sistema teórico. O sistema teórico é fechado, coloca os humanos como sujeitos passivos, enquanto a atividade teórica deve clarificar uma atividade efetiva, é praxis. A teorização não deve ser abandonada ou desprezada, tampouco deve ser subestimada, é preciso compreender a relação entre o fazer e o saber.

19 É necessário cuidado na compreensão de termos que Castoriadis adota para explicar suas ideias, pois em muitos momentos esses termos são tomados de maneira distinta do que é correntemente associado aos mesmos. Assim, a ideia de uma essência do Ser não implica em uma ideia de 'unidade idêntica'. Para Castoriadis (2006, p. 236) "[...] Unidade não quer dizer, evidentemente, invariabilidade através do tempo".
} 
humana), que torna possível o inexistente, significa "[...] ex nihilo, o fazer-ser uma forma que não existia [...]" (CASTORIADIS, 2000, p. 91). Em outro texto ele esclarece:

\begin{abstract}
[...] Há uma natureza na essência do homem que é precisamente essa capacidade, esta possibilidade, no sentido ativo, de fazer ser formas outras de existência social e individual, como se vê quando se considera a alteridade das instituições da sociedade, da língua, das obras e dos indivíduos. Há, portanto, bem entendido, uma natureza na essência do homem que é definida por essa especificidade central, a criação. E esta criação, constatação banal, evidentemente, porém decisiva, não está concluída em nenhum sentido do termo (CASTORIADIS, 1992, p. 88).
\end{abstract}

A criação se manifesta em duas dimensões, uma coletiva e uma individual, que são independentes, mas que se relacionam entre si. A dimensão individual, da psique, é o fluxo de representações, de desejos e de afetos e age de maneira perpétua e contínua em cada indivíduo. Tal fato não implica configurar a criação individual como involuntária ou dissociada do real, mas a afirmação que ela não provém, sim advém ${ }^{20}$. A esta capacidade dá o nome de imaginação radical ou apenas imaginação. Castoriadis sustenta que a imaginação radical não tem qualquer exigência de funcionalidade sendo inclusive, na maior parte das vezes, disfuncional, diferente de outros animais da natureza que detém uma representação do seu universo, mas uma representação dirigida para a funcionalidade, quer de preservação da vida, quer de perpetuação da espécie ${ }^{21}$. Castoriadis (2000) ao exemplificar o traço disfuncional da imaginação aponta como suas criações as ideias de glória, nostalgia e ódio, que são representações/afetos que orientam a vida dos indivíduos, podendo inclusive levá-los à morte. A funcionalidade da psique pode ser encontrada em seu estágio inicial de mônada psíquica, quando ela é voltada para si mesma.

A dimensão coletiva, a social, é o fluxo de representações, de significações que se constroem no interior das sociedades, sempre em uma perspectiva histórica, constituindo o que ele denominou de social-histórico. A essa dimensão da criação denominou imaginário social ou apenas imaginário. É o imaginário que cria a linguagem, as instituições, os

\footnotetext{
20 "Dizer que a figura B é outra que não a figura A significa, portanto, em primeiro lugar, que ela não pode ser deduzida, produzida, construída mediante o que existe "em" A (...). ele vem do nada e de nenhum lugar - que ele não provém, mas que ele advém”. (Castoriadis, 1982, p. 231- grifo nosso).

${ }^{21}$ Retomando a questão da funcionalidade, Noury (2011) aponta que Castoriadis rompe com a perspectiva de funcionalidade encontrada nas filosofias de sua época (no marxismo, estruturalismo, pensamento da ordem de mercado e no darwinismo social). Assim, o tecido social-histórico pensado pelo filósofo grego não tem qualquer relação a algo natural, mas é resultado da capacidade criativa: “[...] Uma concepção funcionalista supõe que todas as instituições sociais e todos os atos dos indivíduos que compõem uma sociedade estão lá para realizar uma certa função; e é necessário tomar a palavra no sentido estrito: função do sistema circulatório em um organismo, etc. Todas as instituições de uma sociedade teriam uma certa função e todos os indivíduos seriam treinados para isso. Todas essas funções devem ser coordenadas por alguma coisa - somos, portanto, obrigados a representar um fim supremo do qual foram colocados, acontecem, ocorrem todas essas funções. (CASTORIADIS, 2002 apud NOURY, 2011, p. 17 - tradução livre). Noury embora reconheça a importância de Castoriadis e, sobretudo, da ideia de imaginário, é um crítico da sua perspectiva de análise social.
} 
costumes, as regras sociais, as leis, as técnicas. E cada sociedade, a cada tempo, estabelece e restabelece seu imaginário. Depois de criadas e consolidadas essas significações imaginárias são chamadas de imaginário social instituído, que se distingue do imaginário social instituinte (competência criadora de novas significações sociais). Ele escolhe o termo imaginário por considerar que essas significações, muitas vezes, não são estritamente ligadas à lógica ou a realidade, p.ex., a ideia de 'Deus', que é para ele uma representação imaginária social, assumida por muitas instituições (a exemplo das igrejas) e portadora de significações que orientam a vida dos indivíduos e da sociedade. Outro exemplo é a instituição 'Estado', que tem como significações imaginárias o capital, a mercadoria, o juro etc. Considera ainda que, o imaginário é produto de um coletivo anônimo. Ainda na dimensão de criação coletiva, Castoriadis trata das instituições sociais, que engendradas de significações imaginárias sociais consolidadas e compartilhadas são responsáveis pelo processo de fabricação social, de socialização dos humanos e de constituição das sociedades. É o magma de significações imaginárias sociais, dentro dos limites de uma dada instituição social, que definem o que é realidade, o que conta e o que não pode ser contado. Nesse sentido, esse magma é responsável pela manutenção do status quo e da coesão social.

Castoriadis enfatiza que os conceitos imaginação e imaginário (produtos da capacidade de criação do humano) estão historicamente relacionadas a ideias insuficientes para pensá-las de forma mais ampla ${ }^{22}$. É preciso abandonar uma noção superficial desses conceitos, por vezes, negativados ou subestimados, ligados à fantasia, ao que se distancia do real, do racional. Estes conceitos, para o pensador, não estão apenas associados à representação da realidade, ou mesmo a combinações de imagens que a percepção possa estabelecer, sendo esta apenas uma de suas funções. À ideia de imaginação como fundadora de representação do real, das percepções, deu o nome de imaginação segunda. Consideramos, como Koutsogiannis (1999, p. 12), que a ideia de imaginário não está associada a "esquemas essencialistas de determinação", a medida em que é condição de permanência e identidade, ao mesmo tempo é condição de mudança e instauração de novas formas de significações. Tal aspecto é fundamental a definição de criação em Castoriadis, que não exige determinação absoluta e nos possibilita pensar sobre a Ciência e sobre a Educação Científica que opera no sentido de que conhecer é dar origem, estabelecer uma determinação. Situando-se "antes e além da oposição entre verdade e falsidade" o imaginário como criação é essência não como unidade, como pode parecer à primeira vista, mas essência enquanto imanência.

Castoriadis afirma que "a história da humanidade é a história do imaginário humano e das suas obras" (CASTORIADIS, 2000, p. 89). A partir dessa afirmação é possível compreender que o autor explica o nascimento da sociedade e sua evolução no tempo a partir do conceito de imaginário e suas transformações. As significações, o imaginário social, mudam ao longo da história. Por exemplo, na democracia grega, os cidadãos eram

\footnotetext{
${ }^{22}$ Sobre como esses conceitos foram sendo concebidos ao longo do tempo por diferentes pensadores ver: $A s$ Encruzilhadas do Imaginário e da Imaginação (CASTORIADIS, 2000, p. 89-108).
} 
considerados 'todos iguais' e semelhantes e decidiam a gestão da polis. Mas, quem eram esses cidadãos? Os iguais desse mundo social-histórico são os seus pares, as mulheres e escravos não eram considerados cidadãos, portanto, não eram iguais. Com a Revolução Francesa, que traz o lema 'Liberdade, Igualdade e Fraternidade', a significação imaginária de igualdade é ampliada e universalizada, devendo valer 'para todos'. O 'para todos' que se constrói na modernidade é uma outra significação imaginária social instituída.

A autonomia também apresenta duas dimensões, uma individual e uma coletiva, estritamente relacionadas. No exercício reflexivo de pensar o desenvolvimento da autonomia, Castoriadis buscou compreender a dinâmica que se estabelece entre "indivíduo" 23 e sociedade, o desvelamento do social-histórico (o mundo dos sentidos, das significações). Castoriadis não se furtou a responder questões do tipo: "[...] O que vem "primeiro", o indivíduo ou a sociedade? A sociedade produz os indivíduos ou então os indivíduos produzem a sociedade?" (CASTORIADIS, 2006, p. 57). Assumiu que a resposta a essas questões passa por abandonar a tradição filosófica greco-ocidental no que compete a subjetivação de determinadas categorias/conceitos: "[...] podemos ver um tipo de relação inédita e original, impossível de pensar sob as categorias do todo e das partes, do conjunto e de seus elementos, do universal e do particular" (2006, p.123). É enfático ao afirmar que "o indivíduo é a sociedade", não há, pois, oposição entre indivíduo e sociedade, e sim entre psique e sociedade. O indivíduo é formado em um processo de socialização ${ }^{24}$ (CASTORIADIS, 1982; 2002; 2006).

De acordo com Castoriadis (2006, p. 122), “[...] A sociedade é obra do imaginário instituinte. Os indivíduos são feitos, ao mesmo tempo eles fazem e se refazem, pela sociedade cada vez instituída: num sentido, eles são a sociedade”. Tendo em conta que, muitas vezes, nos encontramos 'presos' ao que nos foi instituído, nesse caso, as categorias supracitadas, fixos a uma espécie de binarismo que de alguma forma está dentro da constituição lógica da nossa linguagem ${ }^{25}$. O que Castoriadis propõe vai de encontro a essa lógica, posto que a sociedade é o indivíduo que a constitui, logo, o indivíduo não é parte enquanto a sociedade é o todo.

Como dissemos antes, para o autor, as instituições sociais são responsáveis de constituição das sociedades, e sobre isso menciona duas formas de assegurar a validade das instituições: (1) por coerção/sanção; ou (2) por adesão/legitimidade. Na coerção/sanção acontece uma validade de forma superficial, já na adesão/legitimidade a validade é mais ampla. Cada sociedade desenvolve um modo de ser próprio do social-histórico, ou seja, cada

\footnotetext{
${ }^{23}$ Foi colocado indivíduo entre aspas pois Castoriadis faz uma distinção entre o indivíduo e a psique. A psique é uma instância do indivíduo, que com o processo de socialização torna-se a própria sociedade. Ele afirma, pois, que não há distinção entre indivíduo e sociedade e sim entre psique e sociedade.

${ }^{24}$ Contrariando Max Weber e seu método individualista, que consiste na ideia de ser possível compreender a sociedade a partir de um sentido para os indivíduos singulares (CASTORIADIS, 1982).

${ }^{25}$ Por exemplo, temos em lógica, incorporada na linguagem, o princípio da não contradição, em que é vedada a uma proposição ser verdadeira e falsa ao mesmo tempo; e o princípio do terceiro excluído, onde uma proposição ou é verdadeira ou é falsa, ou seja, não há a possibilidade de uma terceira condição.
} 
sociedade cria um magma ${ }^{26}$ de significações imaginárias sociais, originando uma espécie de rede de significações imaginárias que produzem uma dada realidade social-histórica. Um exemplo de significação imaginária social é a ideia de 'desenvolvimento', que pressupõe uma linha de chegada, um fim. O termo desenvolvimento ganhou significado de aumento, de crescimento, mas crescimento de um tipo determinado e não qualquer tipo de crescimento, o crescimento econômico e das forças produtivas. Várias são as razões para que a sociedade estabelecesse esse significado com a ascensão da burguesia, a ideia de progresso por trás da ideia de racionalidade impôs um modelo do que deve ser uma sociedade desenvolvida. Isso é uma criação humana, embora a instituição se fortaleça na medida em que deixa de ser concebida como criação.

Em sua dimensão coletiva/social a autonomia é o reconhecimento das instituições enquanto criação da sociedade. O contrário de uma sociedade autônoma é uma sociedade heterônoma. Afirma Castoriadis que um dos grandes erros apresentados, sobretudo pelo marxismo e pelos movimentos de esquerda, é a ideia de que a heteronomia é a exploração por parte de um grupo, de uma camada social particular, considerando ser esta apenas uma das possíveis manifestações da heteronomia. Para ele, a evidência de que a heteronomia não está associada a uma classe é o fato dela existir em sociedades primitivas, em sociedades não divididas em classes. A heteronomia seria, portanto, a ideia de que as instituições são parte de um ente transcendental e não uma criação da própria sociedade, “[...] a heteronomia das sociedades é "natural'" (CASTORIADIS, 2006, p. 37). Assim, o reconhecimento por parte da sociedade de que suas instituições, suas leis, suas normas, seus valores etc. são constructos próprios, obras de sua autoria, e a possibilidade de questioná-los e modificá-los é a quebra da condição de heteronomia.

Dois traços, pois, marcam uma sociedade heterônoma: i) ocultação da auto instituição, ocultação da realidade que as instituições são construções de um coletivo anônimo, e que se auto instituem. As instituições se estabelecem dissimuladamente, como tendo origem fora do alcance dos humanos, o que as blindam das críticas e contestações internas e externas, é o caso, por exemplo, das religiões; ii) a ocultação da auto alteração, ocorrência de alterações dentro das instituições dada a capacidade de criação, do imaginário radical e das alterações do imaginário social instituído, ainda que as alterações sejam, geralmente, lentas e não-conscientes.

Referente à dimensão individual, da psique ${ }^{27}$, Castoriadis define autonomia como “[...] domínio do consciente sobre o inconsciente" (CASTORIADIS, 1982, p. 123). É, "[...] a

\footnotetext{
${ }^{26}$ Magma tem como definição: “aquilo de onde se podem extrair (ou: em que se podem construir) organizações conjuntistas em número indefinido, mas que não podem jamais ser reconstruído (idealmente) por composição conjuntista (finita ou infinita) destas organizações" (CASTORIADIS, 1982, p. 388). O magma é uma espécie de teia/rede de coexistência dos diferentes sentidos construídos pelo humano, é o mundo das significações.

27 Rovira (2003) chama a atenção para o fato de Castoriadis utilizar a palavra 'psique' em lugar de 'mente', evidenciando sua filiação com a Psicanálise, muito mais do que com a filosofia dominante em seu tempo. A mente foi um conceito bastante estudado no campo da filosofia desde o seu surgimento.
} 
instauração de uma outra relação entre o discurso do Outro e o discurso do sujeito" (p. 126). Visto que o indivíduo é um ser social-histórico e que todo o conteúdo do pensamento é feito pelo mundo, não é dado conceber a autonomia como a "[...] eliminação pura e simples do discurso do outro, e sim a elaboração desse discurso, onde o outro não é material indiferente, porém conta para o conteúdo do que ele diz [...]" (p.129). Castoriadis reconhece que mesmo em sua dimensão individual o Outro está presente, de modo que, "a autonomia só é concebível, já filosoficamente, como um problema e uma relação social” (CASTORIADIS, 1982, p.130), daí tem-se que a dimensão individual não se desliga da social e vice-versa. Ainda de acordo com Castoriadis: "meu discurso deve tomar o lugar do discurso do Outro, de um discurso estranho que está em mim e me domina: fala por mim" (CASTORIADIS, 1982, p.124). Notemos que o que é fundamental é o 'domínio', ou seja, a consciência, o entendimento, do discurso do Outro que é apropriado pelo sujeito. O Eu tem papel ativo, pois encontra-se na instância da decisão.

Castoriadis explicita a relevância das ideias de Freud para o desenvolvimento de seu pensamento. $\mathrm{O}$ trecho que se segue aponta como vai abordar o que chama de instituição social-histórica do indivíduo, ou seja, a transformação da "mônada psíquica" social, o que implica pensar a psique, a partir das contribuições de Freud alinhadas a categoria de imaginação radical e imaginário:

\begin{abstract}
A discussão se fará a partir da concepção freudiana, que não se trata de aprimorar ou refazer, mas sim de esclarecer de outra maneira, a partir desses dois temas que permaneceram para ela, e não por acaso, pontos cegos: a instituição socialhistórica e a psique como imaginação radical - isto é, essencialmente como emergência de representações ou fluxo representativo não sujeito a determinidade (CASTORIADIS, 1982, p. 316).
\end{abstract}

Um dos pontos que institui o núcleo duro da Psicanálise, ponto também central no pensamento de Castoriadis, é a aceitação de que o domínio da psique é o domínio do sentido, da representação, do significado ${ }^{29}$. O humano é sentido encarnado, o que significa que é possível compreendê-lo a partir daquilo que lhe é significado, das representações por ele assumidas, e, talvez por isso a importância que Castoriadis atribui a Psicanálise, por ela buscar compreender a gênese e o desenvolvimento dos significados para os indivíduos, possibilitando ao próprio indivíduo entender a sua história como criação. Mas, a questão do sentido, da representação, do significado não é compreendida apenas em sua dimensão

\footnotetext{
${ }^{28}$ Castoriadis toma o termo 'mônada' de Leibiniz, e o utiliza com o mesmo sentido por ele empregado (como uma unidade primordial). É a 'mônada psíquica', ou apenas 'mônada', um estado inicial da psique. A mesma ideia está presente em Freud, no qual seria a "mônada" um estágio, uma espécie de casulo primário, que ele chama de "autismo".

${ }^{29}$ Em sua tese de doutoramento, Lobo (2011) discute a reinvenção do sujeito no pensamento filosófico e político de Castoriadis. O autor aponta aproximações e afastamentos do pensamento desse filósofo em relação às psicanálises lacaniana e freudiana. Afirma que em Castoriadis "o sentido é a 'resposta ontológica' em face do Caos, isto é, do indeterminado' (LOBO, 2011, p. 29).
} 
individual: haja vista a importância do histórico-social, indivíduo e coletivo estão sempre entrelaçados.

A autonomia individual não se realiza na medida em que o sujeito se afasta do Outro, mas no reconhecimento da existência do Outro em si e da possibilidade de negação desse, assumindo outras vozes. Como o discurso do Outro habita em mim? Para Castoriadis não há indivíduo fora da sociedade, tampouco sociedade que não seja instituída pelo indivíduo. Pelo processo de socialização o $E u$ é formado em toda a sua individualidade, em constante oposição entre a sociedade e a psique. Assim, é razoável acreditar que a autonomia só pode ser consumada a partir da busca pela autonomia do outro, ou seja, mais que um projeto de indivíduo autônomo é necessário um projeto de coletivo autônomo.

Vale destacar que Castoriadis não foi um pensador que se debruçou sobre os problemas da Educação, seus temas de maior intensidade encontram-se no campo da Filosofia, da Economia, da Política e da Psicanálise. Entretanto, aborda a questão da educação no Capítulo II de A Instituição Imaginária da Sociedade (no subtítulo Teoria e Projeto Revolucionário ao tratar de sua ideia de praxis), e em diversas passagens de suas obras ele reconhece a educação como um dos pilares do desenvolvimento de um projeto de autonomia, assim como o é a Política e a Psicanálise. Reconhece que não é apenas a escola a responsável pela educação dos indivíduos, são todas as instituições que compõem e impõem seus valores sobre esses indivíduos, defendendo que "[...] a educação começa com o nascimento e termina com a morte" (CASTORIADIS, 2000, p. 202). Nesse sentido, é preciso ter em mente que a escola é um dos espaços em que a autonomia pode e deve ser desenvolvida, mas não é o único espaço em que se pode realizar, e a educação por ele refletida é a educação de uma maneira mais geral, e não apenas a escolar. Considerando, como visto anteriormente, que de forma geral, as instituições são reprodutoras e responsáveis pela alienação dos sujeitos, as instituições de ensino passam a ser fundamentais na promoção da autonomia. Para muitas pessoas seria o único ambiente em que esse projeto poderá minimamente ser pretendido.

A autonomia como é pensada no ideário comum atende ao modelo liberal, à retórica neo-gerencial, sobretudo quando aparece como sinônimo da capacidade de realizar por si mesmo, de ser engenhoso. Na Pedagogia aparece como potencial para administrar sua própria aprendizagem. Mas, tais aspectos estão intimamente ligados a capacidade de adaptação, de manutenção da estrutura e não de transformação, de revolução, como pensado por Castoriadis. Uma das mais significativas diferenças é que a autonomia castoriadiana não é um estado, não é uma competência adquirida de uma vez por todas, mas um processo sem fim. Requer um espírito de permanente questionamento do que é instituído, uma capacidade permanente de questionar nossas instituições sociais e mesmo as próprias crenças, valores, aquilo que dá sentido a cada indivíduo (TOMES, 2013).

Desta feita, considerando que na perspectiva de Castoriadis a disposição para a criticidade é condição para realização da autonomia, pretendemos discutir na próxima seção como a autonomia é fundamental para a formação humana em tempos ditos de pós-verdade. 


\section{Autonomia e Pós-Verdade}

Como discutido anteriormente, a concepção ontológica em Castoriadis concebe o sujeito não apenas em sua individualidade, mas como a própria sociedade em uma lógica que rompe com a dicotomia indivíduo x sociedade. Assim, a autonomia possui duas dimensões: a coletiva, na qual implica reconhecer que a própria sociedade é instituída, ou seja, suas instituições sociais e suas significações sociais instituídas são criações de um coletivo anônimo; e na individual, na qual sua própria constituição é resultado de discursos de outros, ou seja, é necessário reconhecer que os discursos em si são produtos de outros discursos que circulam, também produto da criação humana. Tal condição implica a disposição para a crítica e autocrítica permanente, uma postura constante de questionamento.

Dentro do campo das comunicações sociais a pós-verdade passou a ocupar o interesse de especialistas (GIACOIA JR., 2018; MCINTYRE, 2018). O termo ganhou notoriedade quando o dicionário Oxford o adotou como palavra do ano de 2016, tal fato passou a fomentar reflexões tanto no campo da Comunicação Social quanto em Filosofia, Educação etc. De modo geral, o debate gira em torno da relativização do conceito de verdade. De acordo com o dicionário, a pós-verdade é alusiva a "circunstâncias nas quais fatos objetivos são menos influentes na formação da opinião pública do que apelos emocionais e crenças pessoais" (OXFORD DICTIONARY, 2016, tradução livre). A escolha ocorreu em função da explosão do uso desse termo, o que indica uma macro percepção dessa condição.

É importante estabelecer uma diferença entre Fake News e Pós-Verdade. De acordo com matéria publicada na revista Science, autores definem como notícias falsas as "informações fabricadas que imitam o conteúdo da mídia de notícias na forma, mas não no processo ou intenção organizacional" (LAZER, et al., 2018, p.1094, tradução livre). Tal definição coloca as fakes news no campo da informação que é construída com a deliberada intenção de mentir. Interessante observar, de acordo com essa definição, que as notícias falsas são construções deliberadas de fatos falsos com alguma intencionalidade que imita o conteúdo de mídia tradicional na sua forma. Sob tal aspecto poder-se-ia questionar a neutralidade e intencionalidade das mídias convencionais, que são permeadas por interesses e que podem ser parciais, isso tudo é possível (o que é verdadeiramente aplicável às Ciências), mas não é nosso objetivo adentrar aqui nessa discussão. O que a pesquisa acima menciona é que socialmente há uma pactuação quanto às normas que regem a prática jornalística, dentro desse cenário, a objetividade e o equilíbrio, e que as notícias falsas aproveitam da forma e da credibilidade que essas instituições ainda dispõem ${ }^{30}$.

\footnotetext{
30 Tal perspectiva é consistente com a análise do discurso de abordagem semiolinguística de Charaudeau (2005; 2008), que advoga que todo o discurso é envolvido por contratos de comunicação (que não são normas de sentidos, mas das condições de realização dos textos). Assim sendo, a linguagem não é plena de liberdade uma vez que é mediada por contratos socialmente construídos e socializados, que são restritivos e que pactuam normas do dizer. Ainda sobre uma pactuação da objetividade e do equilíbrio das mídias tradicionais ver: The Rise of Social Media and the Problem of Fake News (MCINTYRE, 2018).
} 
Considerando o que dissemos até aqui, pós-verdade não pode ser confundida com fake news. A pós-verdade pressupõe a perda de nexo com o real, com o que é objetivo, ou verificável, passando a acreditar unicamente no que condiz com suas crenças e apelos emocionais. Pela definição apresentada pelo dicionário Oxford, a Pós-Verdade corresponde a perda da primazia da verdade.

Concordamos com Giacoia Jr (2018) no entendimento de que o movimento de PósVerdade, que se supõe apoiado em perspectivas filosóficas encontradas em Friedrich Nietzsche e Michael Foucault ${ }^{31}$ por exemplo, responsáveis por relativizar a verdade, trazem uma leitura abreviada desses autores. $\mathrm{O}$ que tais autores propõem é uma mudança ontológica do estatuto da verdade, postura essa que não é vista no movimento de Pós-Verdade. Em outras palavras, o que é possível perceber nesse movimento (Pós-Verdade) não é uma crítica do Ser em si que configura a verdade, não é sua elaboração enquanto um construto. Não há um questionamento da verdade ou daquilo que configura suas bases, ao contrário, o que há é uma reafirmação da verdade (de uma verdade particular). É fácil observar que um indivíduo que aceita uma afirmação de conhecimento (ou notícia) que se encontra em acordo com sua crença o faz em virtude de que essa crença é a sua verdade (ou a compõe, ou a ratifica) e, que uma afirmação de conhecimento (ou notícia) que não coincida com essa verdade não é sequer posta em suspeição. Todos têm certezas, a internet ampliou o espaço de divulgação de certezas. Analisar proposições impõe a disposição para a (auto)crítica, impõe uma postura autônoma.

Reafirmamos que a autonomia, no tocante ao princípio relacionado à disposição para a criticidade, constitui-se como horizonte em oposição a ideia de Pós-Verdade não pela relativização da verdade, mas pela crítica a verdade. Tal orientação não implica adesão ao ceticismo ou ao relativismo ingênuo. $\mathrm{E}$, uma formação científica sólida pode e deve problematizar o dogmatismo científico preservando valores que não caros as Ciências, que dentro de um quadro situado social-historicamente ajuda a validar conhecimentos em disputa, valores como capacidade de predição, apoio experimental, formalização matemática, coerência interna, capacidade de convencimento dos pares, entre outras.

Especificamente no campo do EC, um exemplo apontado por Monteiro (2014) buscou investigar a compreensão de estudantes sobre alguns aspectos de Natureza da Ciência $(\mathrm{NdC})$ a partir da aplicação de um questionário. Duas perguntas eram relacionadas à provisoriedade do conhecimento: a primeira se os conhecimentos científicos (leis, princípio, teorias) uma vez estabelecidos são definitivos, sendo que aproximadamente $89 \%$ dos(as) estudantes responderam não serem definitivos. A segunda pergunta apontava a possibilidade da Teoria da Relatividade Restrita (TRR) perder a validade. Os(As) estudantes dividiram-se com aproximadamente 37\% afirmando que embora possa sofrer alteração, a TRR não será refutada e, apenas $11 \%$ que o conhecimento científico é um campo de verdades provisórias,

\footnotetext{
31 Poderíamos acrescentar Castoriadis entre outros (sobretudo os de tendência pós-estruturalista), mas para manter coerência com o que o Giacoia $\operatorname{Jr}$ (2018) defende, cito apenas os que ele mencionou.
} 
podendo mudar em qualquer tempo. Para esses(as) estudantes, embora haja a compreensão que as Ciências são campos em que questionamentos os são constitutivos e podem mudar com o tempo, para as teorias que aparecem muito bem fundamentadas matemática e experimentalmente e com um amplo espectro de fatos que a corroboram, passa ser difícil assumir que um sistema assim bem ajustado possa não corresponder a uma realidade objetiva/verdade (e não a um modelo). Os/as estudantes quando confrontados com algo que acreditavam corresponder a verdade, tiveram dificuldades de aceitar uma possível refutação. Assim, é necessária que a disposição para a crítica seja uma atividade constante. Ao longo da criação das Ciências, verdades foram sendo questionadas, essa é uma prática que compõe o empreendimento científico. O movimento natural em Aristóteles foi questionado por Filopono (MONTEIRO; MARTINS, 2014); Newton questionou a perspectiva de movimento em Descartes (MARTINS, 2014); Newton questionou Hooke sobre a teoria das cores (SILVA; MARTINS, 2003); Bohr questionou o modelo átomo de Rutherford (PEDUZZI; BASSO, $2005)$ etc. Em resumo, o EC também pode contribuir para ajudar estudantes a desenvolverem uma disposição contínua para o questionamento, na medida em que o enfatiza como uma prática dessas Ciências.

Segundo Castoriadis, o Projeto de Autonomia se relaciona a três campos mais diretamente: a Política, a Educação e a Psicanálise. O que há em comum em cada um desses campos para que o projeto possa ser associado a esses? É a possibilidade que esses campos dão ao surgimento de interrogações ilimitadas, interrogações que incidem sobre as significações sociais instituídas: "[...] O surgimento da interrogação ilimitada cria um eidos histórico novo, - a reflexividade no sentido pleno, ou auto-reflexividade, como o indivíduo que a encarna e as instituições onde ela se instrumenta. [...]" (CASTORIADIS, 2006, p.139).

No debate que envolve as afirmações de conhecimento modelados pelas Ciências e afirmações de conhecimento que não tem base nessas, a inclinação para um lado ou para o outro não é apenas uma questão de uso da razão, quando compreendemos que a própria razão é modelada socialmente. A razão não é uma baliza que pode ser tomada como um dado. Segundo Castoriadis, uma análise histórica ou diacrônica aponta para diferentes formas de racionalidade. Tampouco é possível afirmar "formas cada vez mais elevadas de racionalidade" (CASTORIADIS, 2007, p. 51). Uma pergunta importante que ele nos faz é: "em que a racionalização de uma crença difere da filosofia?"32 (CASTORIADIS, 2007, p. 56) e nos responde: a Filosofia não tem nada para salvar. Decerto que as Ciências enquanto instituição social, como todas as demais, tem como finalidade salvar sua própria existência e exerce nessa tarefa as demais representações que potencializam essa existência. Mas, a Ciência enquanto produto se constitui a partir da mesma base que a Filosofia, ou seja, sob o questionamento permanente de sua produção, não tem que salvar o seu conteúdo. Portanto, temos como prática que faz parte da dinâmica da Ciência o questionamento permanente de

\footnotetext{
32 Nesse trecho, Castoriadis menciona apenas a Filosofia enquanto campo que se propõe a essa disposição de questionamento incessante.
} 
suas próprias verdades. Essa característica, ao nosso ver, é uma das maiores distinções das Ciências de outras fontes de verdades.

Seria este questionamento permanente uma alternativa para as afirmações de conhecimento neste contexto? Castoriadis chama a atenção para a concepção de que uma situação da interrogação contínua poderia conduzir ao ceticismo e, tudo acabar sendo de algum modo crenças. Como saber quais afirmações valem mais que outras, como estabelecer no que acreditar? A ideia de demonstração de todas as afirmações é inaceitável já em Aristóteles, o que nos aponta a inadequação da prova como elemento que demarca o aceitável do não aceitável ${ }^{33}$. E afirma que para não cair no ceticismo (que embora válido do ponto de vista da Filosofia, é muito perigoso) alegando ser necessário parar os questionamentos em algum ponto, "sabendo sempre que lá onde parou não há senão pontos provisórios de ancoragem que serão retomados na sequência” (CASTORIADIS, 2007, p.61).

É a análise crítica das afirmações de conhecimento que situa a autonomia. Defendemos que uma das dimensões da autonomia diz respeito a sua orientação de disposição para a criticidade. Nesse sentido, conforme a filosofia de Castoriadis, tal disposição é considerada como um estado de questionamento permanente (crítica/reflexividade e autocrítica/auto reflexividade), podendo parecer paradoxal pensar a autonomia em oposição a pós-verdade quando se concebe nessa uma possível crítica a verdade. Uma interrogação que nos parece importante e discutida por Castoriadis é: todos os pontos de vista têm valor idêntico?

No contexto da sala de aula, a disposição para a criticidade como uma dimensão da autonomia se relaciona com as afirmações de conhecimento da ciência. A sala de aula é, em geral, um ambiente de compartilhamento de verdades, de um conjunto de saberes que foram construídos, legitimados e socialmente aceitos pela comunidade científica. Como equilibrar as verdades científicas com a disposição para formar para a crítica e a autocrítica? Como o EC pode lidar com essas questões?

Segundo Lazer et al. (2018, p. 1095 - tradução livre) "os indivíduos tendem a não questionar a credibilidade das informações, a menos que elas violem seus preconceitos ou sejam incentivadas a fazê-lo". Ou seja, como é possível lidar com a opção pela crença ou por aquilo que é mobilizado pelas emoções em detrimento daquelas objetivamente factual, sabendo que tal tendência tem implicação também no EC? ${ }^{34}$ Acreditamos que cabe também ao EC incentivar os(as) estudantes a desenvolverem a disposição constante para questionar.

\footnotetext{
33 Ver sobre o Trilema da Aristóteles na seção intitulada 'Os princípios da Impotência da Epistemologia', em Martins (1999).

34 Temos presenciado um aumento na perspectiva de aceitação do terraplanismo, do movimento antivacinas, da negação do aquecimento global antropogênico etc. Acreditamos que, quando se adota qualquer dessas perspectivas, tem-se as mesmas como verdades que não podem ser colocadas a prova, não é a relativização da verdade, como mencionamos, mas a adoção dessas como verdade. Acreditamos que tal problema pode ser superado na medida da disposição para a crítica (nesses casos, mais que a crítica, é necessária a autocrítica).
} 
A defesa da ideia de que as Ciências da Natureza têm a capacidade de sublimar seus estágios de desenvolvimento, de modo que sua historicidade se perde, a lucidez sobre a sua criação se esvai e fortalece os ideais de determinidade e verdade, apoia a necessidade de exercer uma atividade docente que valorize essa historicidade, como é expresso por Castoriadis (1997, p. 203) a seguir:

Esse progressivismo cientifico pode hoje achar seu lugar entre as grandes ilusões fecundas da história. O incontestável progresso da ciência não é a acumulação de verdades, construção das alas de um edificio acrescentando-se harmoniosamente umas às outras pelo trabalho de operários curiosamente condenados a ignorar para sempre o plano de conjunto. Certamente também não é, como a decepção levou talvez alguns a dizê-lo, simples eliminação de erros, falsificação de hipóteses forjadas, frota espectral de teorias desarmadas. [...].

Neste ponto de vista, no tocante a dinâmica de sala de aula, a escolha sobre $o$ que ensinar (embora não deva ser uma atividade exclusiva desse, majoritariamente o é) faz parte da atividade docente. O objeto ensinado é o campo das Ciências da Natureza, que tem um corpo de conhecimento sistematizado, mas tem um desenvolvimento, circunscrito em um espaço e tempo específicos, e constitui uma instituição social com significações sociais que tem/sofre implicações sobre a sociedade. Todos esses elementos são importantes como conteúdo a ser aprendido em sala de aula. É interessante também para refletir sobre os usos dos 'avanços' científicos-técnicos e as implicações no âmbito do social-histórico, que no EC podemos pensar como as relações entre ciência, tecnologia e sociedade. O saber das/sobre Ciências pode possibilitar o exercício da reflexividade na medida em que ela é um instrumento portador de um magma de significações imaginárias que podem/devem ser apropriadas pelos(as) estudantes (e questionadas também), assim como também possibilita a auto reflexividade na medida em que é possível a partir da contribuição desse saber questionar as próprias significações.

Difícil e não consensual é definir o que é a Ciência. Entretanto, caminhando na direção que propôs Martins (1999), ao estabelecer o que não é Ciência, pode-se afirmar que se dispõe de critérios dentro de um espectro localizado e condicionado social e historicamente permitindo avaliar e orientar suas pesquisas. Ciências não são dogmas, submetidas constantemente ao escrutínio dos seus criadores. A própria história das Ciências é histórica, não se pode negar as transformações das narrativas sobre o desenvolvimento científico ao longo do tempo (CASTORIADIS, 1987; MARTINS, 2001; FORATO, 2008).

Defendemos mais de perto as abordagens em História, Filosofia e Sociologia das Ciências (HFSC) e em Argumentação Científica (AC) enquanto uma ferramenta didática com potencial didático para ensinar Ciências e sobre Ciências. Acreditamos que as ferramentas são 
neutras $^{35}$. Embora cada uma dessas temáticas tenha um corpo teórico extenso, com múltiplas facetas, o contorno que é dado a essas abordagens para que elas não se tornem um dogma depende do(a) professor(a) do entendimento que ele(a) tem sobre as Ciências, sobre as ferramentas de ensino e, sobre a formação humana.

\section{Agradecimento}

O presente trabalho foi realizado com apoio da Coordenação de Aperfeiçoamento de Pessoal de Nível Superior - Brasil (CAPES) - Código de Financiamento 001.

Agradecemos à Universidade Federal Rural do Semi-Árido (UFERSA) pelo apoio do afastamento para realização do Doutorado e, ao grupo de estudos e pesquisa Argumentação e Ensino de Ciências - ArgEC (UFRN) pelas importantes contribuições ao longo desse processo.

\section{Referências bibliográficas}

ADORNO, T. W. Educação e Emancipação. Tradução: Wolfgang Leo Maar. In: Educação e Emancipação. Rio de Janeiro: Paz e Terra, 1995. 87p.

ALBUQUERQUE JÚNIOR, D. M. Por um Ensino que Deforme: o docente na pósmodernidade. In: PINHEIRO, A. da P.; PELEGRINI, S. C. A. (Org.). Tempo, Memória e Patrimônio Cultural. 1. ed. Teresina: EDUFPI, 2010. v. 1, p. 55-72.

ALCÂNTARA, M. C. de. A montagem de Redes Históricas no Ensino: uma visão complexa da ciência. 2018. 204 f. Tese (Doutorado em Ciência, Tecnologia e Educação) Centro Federal de Educação Tecnológica Celso Suckow da Fonseca, Rio de Janeiro.

BERBEL, M. A. N. As metodologias ativas e a promoção da autonomia de estudantes. Semina: Ciências Sociais e Humanas, v. 32, n. 1, p. 25-40, 2011. Disponível em: $<$ http://www.uel.br/revistas/uel/index.php/seminasoc/article/view/10326/10999>. Acesso em: 20 jan. 2020.

BRASIL, L. D. B. Lei 9394/96 - Lei de Diretrizes e Bases da Educação Nacional. Disponível em: <http://www.planalto.gov.br/ccivil_03/leis/19394.htm>. Acesso em: 29 mai. 2020.

\footnotetext{
35 Assumimos que as ferramentas didáticas são neutras, ou seja, não a ferramenta que é a responsável pela adequação ou não aos objetivos que estabelecemos, mas os usos que se fazem dela.
} 
BRASIL, BNCC - Base Nacional Comum Curricular. Disponível em: <http://basenacionalcomum.mec.gov.br/images/BNCC_EI_EF_110518_versaofinal_site.pdf> Acesso em: 29 mai. 2020.

CACHAPUZ, A; GIL PEREZ, D.; CARVAlHO, A. M P.; PRAIA, J; VILCHES, A. A Necessária Renovação do Ensino de Ciências. São Paulo: Cortez, 2005. 263p.

CACHAPUZ, A.; PRAIA, J; JORGE, M.; Da Educação em Ciências às Orientações para o Ensino de Ciências: um repensar epistemológico. Ciência \& Educação, v.10, n. 3, p. 363381, 2004.

CASTORIADIS, C. A Instituição Imaginária da Sociedade. 3. ed. Rio de Janeiro: Paz e Terra, 1982. 418p.

CASTORIADIS, C. As Encruzilhadas do Labirinto I. Rio de Janeiro: Paz e Terra, 1987. $418 \mathrm{p}$.

CASTORIADIS, C. Entrevista ao Agora Internacional no Colóquio de Cerisy, 1990 [Transcrição parcial feita por François Loget y revisada por David Ames Curtis]. Disponível em: $<$ http://uninomadasur.net/?p=864>. Acesso em: 05 jan. 2020.

CASTORIADIS, C. As Encruzilhadas do Labirinto VI - Figuras do Pensável. Lisboa: Instituto Piaget, 2000.

CASTORIADIS, C. As Encruzilhadas do Labirinto IV - A Ascenção da Insignificância. São Paulo: Paz e Terra, 2002. 279p.

CASTORIADIS, C. A Instituição Imaginária da Sociedade III - O mundo Fragmentado. Rio de Janeiro: Paz e Terra, 2006. 293p.

CASTORIADIS, C. Sujeito e Verdade no Mundo Social-Histórico: seminários 1986-1987. Rio de Janeiro: Civilização Brasileira, 2007. 557p.

CASTORIADIS, C. O socialismo do futuro. In: CASTORIADIS, C. et al. A Criação Histórica. Porto Alegre: Artes Ofício, 1992, 140p.

DOSSE, F. Castoriadis: una vida. Buenos Aires: El Cueco de Plata, 2018. 507p.

EL-HANI, C. N.; MORTIMER, E. F. Multicultural education, pragmatism, and the goals of science teaching. Cult. Stud. of Sci. Educ., v. 2, p. 657-702, 2007. 
FERREIRA, T. A. da S. Entendimento, Conhecimento e Autonomia: Virtudes Intelectuais e o Objetivo do Ensino de Ciências. 2015. 132f. Tese (Doutorado em Ensino, História e Filosofia das Ciências) - Universidade Federal da Bahia, Bahia.

FORATO, T. C. M. A Filosofia Mística e a Doutrina Newtoniana: uma discussão Historiográfica. Alexandria - Revista de Educação em Ciência e Tecnologia, v. 1, n. 3, p. 29-53, 2008.

FREIRE, P. Pedagogia da Autonomia: saberes necessários a prática educativa. 5. ed. Rio de Janeiro: Paz e Terra, 2004.

GIACÓIA JR. O. Conferência de abertura do Seminário Pós-Verdade do Instituto de Estudos Avançados Unicamp. Youtube, 15 out. 2018. Disponível em:

$<\mathrm{https}$ :/www.youtube.com/watch?v=SYDSO_zAXMo\&t=48s $>$. Acesso em: 05 jan. 20.

KANT, I. Resposta à Pergunta: o que é o esclarecimento? In: Textos seletos. Petrópolis: Vozes, 1985. p. 100-117.

KOUSOGIANNIS, A. Ideologia e o Projeto de Autonomia na teoria do Imaginário de Cornelius Castoriadis. Tradução: Cynthia Harnlin e Revisão de Maria Elizabete Albuquerque. Estudos de Sociologia, UFPE, v. 2, n. 5, 1999.

LAZER, D. M. J. et al. The Science of fake News. Science, v. 359, n. 6380, p. 1094-1096, 2018.

LIMA. N. W.; NASCIMENTO, M. M. Nos becos da Episteme: Caminhos confluentes para uma contra colonização didática em meio à crise da verdade. Caderno Brasileiro de Ensino de Física, v. 36, n. 3, p. 589-598, 2019.

MARTINS, R. A. O que é Ciência, do Ponto de Vista da Epistemologia? Caderno de Metodologia e Técnica de Pesquisa, v. 1, n. 9, p. 5-20, 1999.

MARTINS, R. de A. História e história da ciência: encontros e desencontros. In: CONGRESSO LUSO-BRASILEIRO DE HISTÓRIA DA CIÊNCIA E DA TÉCNICA, 1, 2001, Évora. Actas... p. 11-46.

MCINTYRE, L. Post-truth. Cambridge, MA: MIT Press, 2018. 
MELO, V. F. de. O Júri Simulado como Recurso Didático para Promover Argumentações na Formação Inicial de Professores de Física. 2016. 152f. Dissertação (Mestrado em Educação) - Universidade Federal Fluminense, Niterói.

MONTEIRO, M. M. Inércia e Natureza da Ciência no Ensino de Física: Uma Sequência Didática Centrada no Desenvolvimento Histórico do Conceito de Inércia. 2014. 230 p. Dissertação (Mestrado) - UFRN, Natal.

MONTEIRO, M. M.; MARTINS, A. F. P. Conteúdos de natureza da ciência no ensino de Física: a controvérsia entre Aristóteles e Filopono. In: ENCONTRO DE PESQUISA EM ENSINO DE FÍSICA, XV, 2014, Maresias, 2014. Atas... São Paulo: SBF, 2014.

MOURA, B. A. Formação crítico-transformadora de professores de Física: uma proposta a partir da História da Ciência. 2012. 309f. 2012. Tese (Doutorado em Ciências) Universidade de São Paulo, São Paulo.

MOURA, C. B. O Ensino de Ciências e a Justiça Social: questões para o debate. Caderno Brasileiro de Ensino de Física, v. 36, n. 1, p. 1-7, 2019.

NOURY, M. Cornelius Castoriadis, Sociologue? critique sociologique de l'ontologie de la création imaginaire sociale. Aspects Sociologiques, v. 18, n. 1, 2011. Disponível em: $<$ https://www.researchgate.net/publication/301266479>. Acesso em: 10 ago. 2019.

OLIVEIRA, D. G. da S. Anarquismo, Autonomia e esclarecimento no objetivo do Ensino das Ciências. 2017. 218f. Tese (Doutorado em Ensino, Filosofia e História das Ciências) Universidade Federal da Bahia e Universidade Estadual de Feira de Santana, Bahia.

PEDUZZI, L. O. Q.; BASSO, A. C. Para o ensino do átomo de Bohr no nível médio. Revista Brasileira de Ensino de Física, v. 27, n. 4, p. 545-557, 2005.

RODRIGUES, N. Educação: da formação humana à construção do sujeito ético. Educação \& Sociedade, ano XXII, n. 76, out. 2001.

ROIZ, D. S. A Filosofia (Da História) De Cornelius Castoriadis (1922-1997). Revista de Teoria da História, ano 1, n. 2, 2009.

SEVERINO, A. J. A Busca do Sentido da Formação Humana: tarefa da filosofia da educação. Educação e Pesquisa, São Paulo, v. 32, n. 3, p. 619-634, set./dez. 2006. 
SOUZA, L. S.; CARVALHO, A. M. P. Ensino de ciências e formação da autonomia moral. In: Congreso Enseñanza de las Ciencias, VII, 2005. Atas... Disponível em:

$<$ https://ddd.uab.cat/pub/edlc/edlc_a2005nEXTRA/edlc_a2005nEXTRAp530enscie.pdf $>$.

Acesso em: 10 abr. 2020.

VALLE, L. do. Cornelius Castoriadis: pistas luminosas para pensar o humano. In: $2^{\circ}$ Encontro ouvindo coisas - experimentação sob a ótica do imaginário. [S.1.: s.n.], 2002.

VALLE, L. Castoriadis: uma filosofia para a educação. Educação \& Sociedade, Campinas, v. 29, n. 103, p. 493-513, mai./ago. 2008. 